\section{Mulheres negras e imprensa feminista: vozes, interseccionalidade e cidadania}

[Black women, and feminist press: voices, intersectionality, and citizenship]

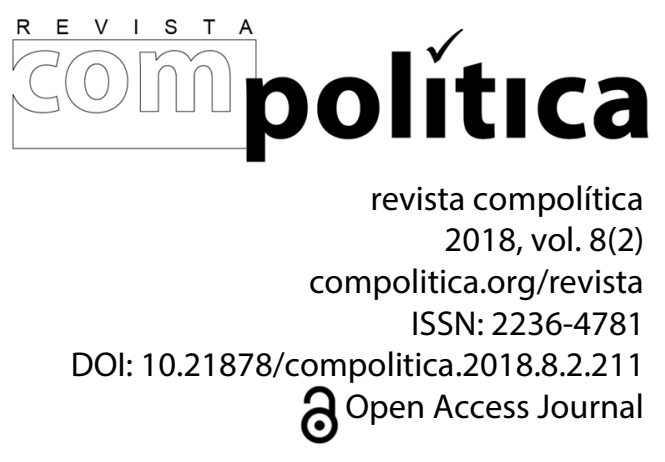

\author{
Viviane Gonçalves Freitas \\ Universidade Federal de Minas Gerais \\ [Federal University of Minas Gerais]
}

\begin{abstract}
Resumo
Este artigo busca compreender como a discussão interseccional se configura em veículos da imprensa feminista, tornando-se uma necessidade premente para o questionamento de um olhar direcionado e padronizador de experiências vivenciadas por um restrito grupo de mulheres - em sua maioria, brancas, heterossexuais e de classe média. Nzinga Informativo e Nós, Mulheres da Periferia são exemplos elucidativos quanto à aplicabilidade do conceito de interseccionalidade na imprensa feminista brasileira, ao trazerem a agenda de raça, classe e gênero, a partir das vozes das mulheres negras, nas lutas por direitos.
\end{abstract}

Palavras-chave: interseccionalidade, imprensa feminista, mulheres negras.

\begin{abstract}
This paper intends to understand how the intersectional discussion is configured in the feminist press, becoming a pressing need to question a directed and standardized view of experiences lived by a restricted group of women - mostly white, heterosexual and middle class. Nzinga Informativo, and Nós, Mulheres da Periferia are important examples of the applicability of the concept of intersectionality in the Brazilian feminist press, by bringing the agenda of race, class and gender from the voices of black women, in the struggles for rights.
\end{abstract}

Keywords: intersectionality, feminist press, black women. 


\section{Mulheres negras e imprensa feminista: voz, interseccionalidade e cidadania}

s passos das mulheres negras, na agenda de lutas por direitos e cidadania, vêm de longe, como nos lembra Werneck (2010). No tocante ao reconhecimento de sua produção de conhecimento acadêmico (hooks, 1995; Collins, 2016), no processo de formação política, principalmente no período da redemocratização (Gonzalez, 1982, 1984) e o questionamento quanto ao feminismo hegemônico - branco, eurocêntrico, heteronormativo - ainda temos muitos passos a dar.

Os primeiros grupos organizados de mulheres negras surgiram também na efervescência dos movimentos sociais das décadas de 1970 e 1980, no interior do movimento negro. De acordo com Gonzalez (1985), isso se explica, em parte, devido aos setores médios da população negra conseguirem entrar no processo competitivo do mercado de trabalho, nos campos mais expostos às práticas discriminatórias de mão de obra. A autora destaca que o desempenho das mulheres negras na formação do movimento negro, no Rio de Janeiro, por exemplo, foi muito importante, tanto para sua fundação quanto para seu desenvolvimento e expansão pelo país.

[...] é no Movimento Negro que se encontra o espaço necessário para as discussões e o desenvolvimento de uma consciência política a respeito do racismo e suas práticas e de suas articulações com a exploração de classe. Por outro lado, o Movimento Feminista ou de Mulheres, que tem suas raízes nos setores mais avançados da classe média branca, geralmente "se esquece" da questão racial [...]. E esse tipo de ato falho, a nosso ver, tem raízes históricas e culturais profundas. (Gonzalez, 1985, p. 100).

Em seus escritos, Gonzalez $(1982,1985)$ ressalta que antes mesmo das organizações do movimento de mulheres negras existirem, ainda no início dos encontros do Movimento Negro Unificado (MNU), havia frequentes discussões sobre o que saía nos noticiários sobre discriminação racial e sobre o período pré-colonial na África. Chegou-se ao ponto de as mulheres fazerem a discussão em separado dos homens, abordando também o machismo 
não apenas dos homens brancos, mas dos próprios negros, e depois todos se juntavam na reunião ampliada chamada "Grupão", quando expunham os resultados da discussão anterior, com o propósito de o conjunto também refletir sobre a condição das mulheres negras.

Principalmente, durante a década de 1980, com a retomada das mobilizações da sociedade civil, o movimento de mulheres negras ganhou expressividade tanto no ativismo negro quanto no feminista, de forma mais ou menos institucionalizada. Mesmo com predominância no eixo Rio-São Paulo, diversos grupos de mulheres negras foram fundados naquele momento, também em outras regiões do país. Entre eles, estavam: Aqualtune (Rio de Janeiro, 1979), Luiza Mahin (Rio de Janeiro, 1980), Grupo de Mulheres Negras do Rio de Janeiro (Rio de Janeiro, 1982), Coletivo Mulheres Negras do Estado de São Paulo (São Paulo, 1983), Nzinga - Coletivo de Mulheres Negras (Rio de Janeiro, 1983), Mãe Andresa (Maranhão, 1986), Maria Mulher (Rio Grande do Sul, 1987) e Mulheres Negras do Espírito Santo (Espírito Santo, 1987) (Freitas, 2017; Rios, 2017; Rios; Freitas, 2018).

No momento em que "as esquerdas titubeavam" em debater questões específicas quanto à homossexualidade e às mulheres, com receio de que pudessem "dividir a luta do operariado", Gonzalez (1985, p. 101) frisa que, no MNU, foi conquistado o direito de discutir, em congresso, as especificidades. Para Rodrigues e Prado (2010, p. 453), as organizações de mulheres negras trazem fôlego novo para o movimento negro, a partir da possibilidade de se pensar a categoria "negro" como articuladora central, embora não seja um dado homogêneo e isento de divergências internas, sendo consideradas pelos homens do movimento como "omissas", "desorganizadas" ou "desinteressadas".

Segundo Carneiro (2003, p. 120, grifo da autora), a diferença de posicionamento das mulheres negras dentro dos movimentos feministas se devia à "consciência de que a identidade de gênero não se desdobra naturalmente em solidariedade racial intragênero". Assim, começaram a enfrentar as contradições e as desigualdades que o racismo e a discriminação racial produzem entre mulheres, em especial, entre negras e brancas no Brasil. Partindo dessa perspectiva, a discussão sobre o termo "interseccionalidade" se faz fundamental para se entender o contexto de luta das mulheres negras, uma vez que a tríade 
gênero-raça-classe, ainda hoje, se apresenta como "incontornável” (Biroli; Miguel, 2015), no que se refere às relações intra e intergênero.

Dessa forma, este artigo busca compreender como a discussão interseccional se configura em dois veículos da imprensa feminista, observadas as devidas diferenças de contextos e plataformas: um jornal - Nzinga Informativo $(1985-1989)^{1}$ - e um site - Nós, Mulheres da Periferia (2012-) $)^{2}$, e se apresenta como uma necessidade premente para o questionamento quanto a um olhar direcionado e padronizador de experiências vivenciadas por um restrito grupo de mulheres, em sua maioria, brancas, heterossexuais e de classe média. Parte-se do entendimento de que a imprensa alternativa, na qual a imprensa feminista se insere, é "um forte indicador da densa produção dos agentes civis desejosos da transformação social por vias democráticas" (Rios; Freitas, 2018, p. 29); o que vale tanto para a década de 1980 quanto para os dias atuais. Assim, ambos os veículos jornalísticos são exemplos elucidativos quanto à aplicabilidade do conceito de interseccionalidade na imprensa feminista brasileira, ao trazerem a agenda de raça, classe e gênero, a partir das vozes das mulheres negras, sujeitos políticos nas lutas por direitos.

O trabalho em tela, a fim de melhor exame dos informativos supracitados, se divide em três seções, além desta introdução e das considerações finais. A primeira delas refere-se ao conceito de interseccionalidade e sua relevância para o entendimento da agenda feminista de modo plural e não universalizante. Na sequência, será abordada a imprensa feminista e as características que a diferenciam tanto da imprensa feminina e quanto da imprensa tradicional. Por fim, por meio da análise de conteúdo, serão analisadas as cinco edições do Nzinga Informativo e o material do site Nós, Mulheres da Periferia, disponível de 2012 a fevereiro/2018, ressaltando o momento histórico e os principais temas abordados pelas publicações.

\footnotetext{
${ }^{1}$ Acervo do Arquivo Edgard Leuenroth (Unicamp) e do Centro Informação da Mulher (CIM). ${ }^{2}$ Disponível em: <http://nosmulheresdaperiferia.com.br/>
} 


\section{A interseccionalidade gênero, raça e classe}

Há algum tempo, interseccionalidade tornou-se uma referência no debate feminista no Brasil e também em outros países. Seja em reflexões acadêmicas ou em debates nos meios digitais, falar sobre características que não podem ser analisadas separadamente, visto que seu impacto sócio-político-cultural se faz de maneira conjugada, acabou ganhando um caráter de novidade, de inclusão, uma tentativa de pensar os feminismos de modo plural.

Entretanto, se a pesquisa se amplia um pouco mais, é possível perceber que a base dessa discussão vem de mais de trinta anos, para falar apenas de Brasil, quando Lélia Gonzalez, ainda na década de 1980, indagava a sociedade e a academia, em particular, quanto às desvantagens e os privilégios sobre o sexo (o termo "gênero" não era tão usual como nos debates atuais), a raça e a classe. Isso sem contar sua proposta de um feminismo transnacional ou "afrolatinoamericano", cujo objetivo era aproximar diversas contribuições culturais e políticas de mulheres de ascendência africana e indígena, com o propósito de se contrapor ao entendimento de um feminismo hegemônico (Rios; Ratts, 2016). Sobre o meio acadêmico em particular, a filósofa "criticava a hierarquização de saberes como produto da classificação da população", ou seja, ao se atrelarem privilégio social e privilégio epistêmico, "o modelo valorizado e universal de ciência é branco" (Ribeiro, 2017, p. 24).

Para Carneiro (2011), a universalização da luta dos movimentos feministas, feita a partir do ponto de vista das mulheres brancas, nega, deslegitima e silencia as mulheres negras, aproximadamente metade da população feminina brasileira. Quase três décadas depois de Gonzalez, Carneiro ainda precisa frisar o mesmo ponto: as mulheres negras são preteridas no mercado de trabalho, no acesso, em promoções e na ocupação de bons cargos, devido ao eufemismo da "boa aparência". Afinal, a predileção é por brancas; se forem loiras, melhor.

[...] o movimento feminista brasileiro se recusa a reconhecer que há uma dimensão racial na temática de gênero que estabelece privilégios e desvantagens entre as mulheres. [...] É a consciência desse grau de exclusão que determina o surgimento de organizações de mulheres de combate ao racismo e ao sexismo, tendo por base a capacitação de mulheres negras, assim como o estímulo à participação política, à visibilidade, à problemática específica das mulheres 
negras na sociedade brasileira, à formulação de propostas concretas de superação da inferioridade social gerada pela exclusão de gênero e raça, à sensibilização do conjunto do movimento de mulheres para as desigualdades dentro do que o racismo e a discriminação racial produzem. (Carneiro, 2011, p. 121-122).

Interseccionalidade, segundo Crenshaw (2002, p. 177), seria, então, "uma conceituação do problema que busca capturar as consequências estruturais e dinâmicas da interação entre dois ou mais eixos da subordinação". O conceito ainda sugere que, na verdade, "nem sempre lidamos com grupos distintos de pessoas e sim com grupos sobrepostos" (Crenshaw, s.d., p. 10). Isso nos leva a pensar que, ao ter por base os critérios da interseccionalidade, sistemas discriminatórios como o racismo, a disputa de classes e o patriarcado passam a ser considerados como variáveis que juntas alteram a estrutura opressora, por meio de ações e políticas específicas, ou seja, em aspectos dinâmicos opostos ao empoderamento. Em especial, as assimetrias advindas do entrecruzamento e da constituição recíproca de gênero, classe e raça, nas palavras de Biroli e Miguel (2015, p. 29), seriam “incontornáveis para a análise das desigualdades nas sociedades contemporâneas".

A ideia de interseccionalidade trazida por Costa (2013, p. 474), com base nos estudos de Crenshaw, trabalha a articulação política entre os movimentos classista, feminista e negro a partir de duas noções importantes para pensar desigualdades: desempoderamento e empoderamento. Pela primeira perspectiva, o conceito refere-se "à maneira pela qual o racismo, as relações patriarcais, a opressão de classe e outros eixos de poder e discriminação criam desigualdades". Em outro sentido - o do empoderamento -, as dinâmicas dos eixos de poder (classe, raça, gênero etc.) podem fazer com que sejam criadas resistências e mobilizações políticas individuais e coletivas entre os membros dos grupos marginalizados.

O legado das lutas das mulheres negras ganha ainda mais força ao se deparar cotidianamente com a vulnerabilidade às agressões sofridas no trabalho, na rua, em casa e via meios de comunicação, em um misto de racismo, misoginia e pobreza. Segundo o Atlas da Violência 2018 (IPEA; FBSP, 2018), em dez anos (2006-2016), o número de mulheres negras assassinadas no país, por 100 mil habitantes, teve um aumento de 15,4\%. Já entre 
mulheres não negras ${ }^{3}$, o percentual teve uma queda de $8 \%$, no mesmo período. Considerando-se que, em 2016, 4.645 mulheres foram mortas, a taxa de homicídio entre as mulheres negras (5,3 a cada 100 mil) e não negras (3,1 a cada 100 mil) apresentam uma diferença de $71 \%$.

Outra pesquisa (Retratos das desigualdades de gênero e raça - IPEA, 2017) revela que não apenas as desigualdades entre mulheres e homens, mas também entre as próprias mulheres se mantêm significativas, o que demanda uma atenção para o que, de fato, significa o empoderamento feminino alardeado atualmente. Segundo o estudo, por exemplo, em 2015, 25,4\% das mulheres brancas tinham 12 ou mais anos de estudo. Em contrapartida, este percentual caía para $11,9 \%$ entre mulheres negras. O sentido era inverso se o período observado fosse de menos de 1 ano de escolaridade: 14,7\% (negras) e 8,6\% (brancas). Quanto à renda familiar per capita, na comparação sexo e cor/raça, os/as chefes de família brancos/as ocupavam o topo da pirâmide salarial, a saber, nesta ordem: (i) homens brancos $(\mathrm{R} \$ 1.642,60)$, (ii) mulheres brancas ( $\mathrm{R} \$ 1.572,50)$, (iii) homens negros ( $\mathrm{R} \$ 896,70)$ e (iv) mulheres negras $(\mathrm{R} \$ 831,30)$.

Dessa forma, ao se discutir as relações de poder imbricadas pela dualidade público-privado, não é possível suspender as diversas correlações existentes entre as variáveis de opressão. Biroli e Miguel (2015) frisam que é necessário ampliar as perspectivas da busca por direitos das mulheres, indo além das considerações baseadas exclusivamente na vivência de mulheres brancas. É imprescindível que, ao se falar de feminismos, sejam consideradas as vivências distintas das apresentadas pelas mulheres de classe média em décadas passadas. O cotidiano de opressão quanto ao sexismo e à divisão sexual do trabalho também se complexifica com o racismo e com as desvantagens de classe, e não é possível se pensar em discriminação sem considerar tais variáveis.

\footnotetext{
${ }^{3}$ Optou-se por manter o termo "não negras", conforme está no Atlas da Violência 2018, entendendo-se a expressão aqui como sinônimo de "brancas".
} 


\section{As mulheres e a imprensa feminista}

A imprensa feminista aqui se insere no debate permeado por duas áreas de conhecimento - a Ciência Política e a Comunicação - que, juntas, suas teorias e reflexões têm muito a acrescentar nas discussões sobre o sujeito plural "mulheres". Ao se estudar a imprensa feminista na Ciência Política, o foco está em como esses grupos de mulheres se articulam para produzir jornais que levam em suas páginas (impressas ou digitais) bem mais do que palavras, notícias, comentários, artigos, charges, resenhas. Nesses veículos estão expressos gritos por liberdade, autonomia, justiça, reconhecimento, democracia e cidadania. Também há o enfrentamento pelas condições abjetas de mulheres consideradas como trabalhadores de segunda categoria, visto que realizam os serviços que ninguém se prontificaria a fazer.

De 1964 a $1980^{4}$, o período da ditadura militar no Brasil, a imprensa alternativa ${ }^{5}$ ou imprensa nanica teve cerca de 150 periódicos, que, diferentemente da grande imprensa, denunciavam, de maneira sistemática, as torturas e as violações dos direitos humanos, além de criticar o modelo econômico. Desse universo, metade completava um ano de existência, muitos ficavam apenas nos dois ou três primeiros números. Quando da reabertura política, a grande imprensa se apropriou de vários temas até então discutidos apenas pelos jornais alternativos, o que fez com que vários jornalistas fossem recontratados. Também o fato de a atividade política voltar às vias democráticas, seja pelos partidos ou pelos jornais, após a anistia, esvaziou a imprensa alternativa que perdeu sua função de espaço de realização sociopolítica - além de seu "monopólio de se opor ao governo". Além do desprezo por questões administrativas, o repúdio pelo lucro e as investidas da censura, os jornais alternativos acabavam por encerrar suas atividades por divergências internas, de cunho político-ideológico (Kucinski, 1991). Ao mesmo tempo em que se apresentavam "como

\footnotetext{
${ }^{4}$ A pesquisa do autor contemplou apenas quinze dos 20 anos de ditadura militar; por esta razão o período mencionado encerra-se em 1980, não em 1985, quando houve as eleições indiretas para presidente da República, cujo vencedor foi o civil Tancredo Neves, tendo José Sarney como vice.

${ }^{5}$ Kucinski (1991, p. XIII) associa o termo alternativa a quatro significados principais: "o de algo que não está ligado a políticas dominantes; o de uma opção entre duas coisas reciprocamente excludentes; o de única saída para uma situação difícil e, finalmente, o do desejo das gerações dos anos 60 e 70, de protagonizar as transformações sociais que pregavam". Já a palavra nanica tem inspiração no formato tabloide adotado pela maioria dos jornais alternativos, enfatizando sua reduzida escala de valores para reprodução.
} 
formas públicas de contestação à ditadura militar", eram "espaços de articulação e visibilidade políticas durante a redemocratização do Brasil" (Rios; Freitas, 2018, p. 29).

Kucinski (1991, p. 79) destaca que foi com atraso de alguns anos, em relação à Europa, que chegou ao Brasil "uma nova combinação de ideias e desejos de luta, um novo ativismo político, contribuindo para o processo de abandono do paradigma clássico de ativismo baseado exclusivamente no conceito de 'luta de classes"”. É com base nessa formação de nichos e de uma especificidade dentro dos próprios movimentos feministas que aqui se começa a abordar a atuação da imprensa feminista no Brasil. Para Leite (2003, p. 240), "a imprensa feminista representou um espaço de experimentação de uma forma muito especial de fazer política, refletindo sobre as descobertas das mulheres sobre si mesmas e sobre as ideias feministas que floresceram na década de 1970".

Cabe salientar que há diferenças significativas entre a imprensa feminina e a imprensa feminista que merecem ser detalhadas aqui. Em primeiro lugar, quando a imprensa feminina surgiu, no século XIX, os textos eram escritos por homens e direcionados para as mulheres, a fim de haver a ampliação dos papéis femininos tradicionais, vinculados ao lar ou ao convento. Mesmo ao longo do tempo, o desenvolvimento das sociedades diversificou as temáticas para literatura e artes domésticas, salientando o caráter secundário do jornalismo que nasceu com a função de entretenimento, utilidade prática ou didática (Buitoni, 2009). Em contrapartida, a imprensa feminista refere-se a um jornalismo feito por mulheres, a respeito das mulheres e para mulheres, com o intuito de ser um espelho fiel delas, com suas contradições, desejos, conquistas, problemas, lutas, questionamentos. As temáticas abordadas transpassam áreas diversas, como saúde, educação, trabalho, sexualidade e política governamental, sem cair em estereótipos e destacando o valor de cada mulher em sua singularidade (Borges, 1982).

Foi na efervescência do debate sobre os direitos das mulheres, da Década da Mulher (19751985), instituída pela Organização das Nações Unidas (ONU), que ganharam fôlego e circularam, na década de 1970, entre os periódicos alternativos, 75 jornais voltados para a agenda feminista, em seus diferentes nichos, como socialistas, lésbicas e sindicalistas (Cardoso, 2004). A imprensa feminista inseria-se nesse montante junto a publicações voltadas para ecologia, humor, prazer, política e economia. Contudo, foram os periódicos 
sobre gênero que tiveram continuidade durante as décadas de 1980 a 2010, enquanto a imprensa alternativa como um todo perdeu força. O Brasil Mulher (1975-1980) e o Nós Mulheres (1976-1978) foram os primeiros jornais feministas, com sede no Brasil, escritos por mulheres e tendo como público principal as mulheres, sendo inseridos nas manifestações do feminismo de segunda onda (Cardoso, 2004; Pinto, 2007). Nas décadas seguintes, surgiram vários outros como o Mulherio (1981-1988), produzido pelas pesquisadoras da Fundação Carlos Chagas, de São Paulo, e o Fêmea (1992-2014), publicado pelo Centro Feminista de Estudos e Assessoria (CFEMEA), com sede em Brasília (Freitas, 2017).

Quanto ao Nzinga Informativo, diferentemente de outros periódicos feministas e de seus grupos editores contemporâneos a ele, como o Brasil Mulher, o Nós Mulheres e o Mulherio, há poucos registros acadêmicos que se atentam para esse importante momento da história do movimento negro e do movimento feminista negro no Brasil. Cabe considerar aqui também que muito pouco se conhece sobre este periódico e sobre o coletivo homônimo de mulheres negras, fundado no Rio de Janeiro, em 1983, por Lélia Gonzalez e outras ativistas negras.

Já o Nós, Mulheres da Periferia surge quase três décadas depois, no momento em que o debate feminista volta a fervilhar na sociedade ocidental, principalmente entre as mulheres jovens, que encontram na internet, diversos canais e plataformas de contato e trocas de experiências, para além de territórios geograficamente fixados. Como o jornal do coletivo carioca, o grupo da periferia de São Paulo, por meio do trabalho jornalístico, estimula a difusão das vozes das mulheres negras, em especial, as periféricas, destacando que as opressões combatidas permanecem as mesmas, na aglutinação de gênero, raça e classe.

Os representantes da imprensa feminista aqui apresentados, mesmo se referindo a dois momentos distintos - o primeiro (Nzinga Informativo), quando ainda começávamos a ter a retomada da democracia após mais de 20 anos de ditadura militar, o segundo (Nós, Mulheres na Periferia), nos dias atuais, difundido por meio de plataformas digitais e com um contato cada vez mais próximo à audiência -, têm em comum uma agenda não abarcada pela grande mídia. As temáticas que são debatidas falam do que, muitas vezes, é considerado menor, sem valor de notícia ou não merecedor de grande destaque por outros 
veículos. Nzinga Informativo se insere entre as publicações da imprensa alternativa dos anos 1970-1980 (Kucinski, 1991); enquanto Nós, Mulheres na Periferia está entre os da imprensa independente, como assim se autodenominam as novas mídias que pautam o "não pautável", comercialmente falando, ou numa perspectiva que foge da cobertura "imparcial e neutra", da segunda década dos anos 2000.

Para Godard (2002, p. 212-213), a imprensa feminista representa a possibilidade de se perceber os processos engendrados de reprodução social e de criação de valor cultural. Com "existência fora do modelo dominante de publicação capitalista, às margens e em oposição, seja por meio de sua posição limite no que diz respeito ao mercado ou quanto a seu compromisso com a ideologia contestatória”, os periódicos feministas, segundo a autora, criam novos circuitos para difundir entre as mulheres saberes e práticas que busquem transformar a condição feminina sob a qual têm sido sujeitadas à opressão sistêmica.

\section{Nzinga Informativo e Nós, Mulheres da Periferia}

Lançado em 1985, no Rio de Janeiro, o Nzinga Informativo trazia, desde seu projeto, uma definição muito direcionada de seus propósitos e público. Por meio de suas páginas, o debate sobre o racismo e o sexismo, que afetavam (e ainda afetam) as mulheres negras sempre teve maior destaque. A luta de classes também circundava as discussões do grupo - principalmente porque o coletivo homônimo foi formado, em 1983, a partir da associação de mulheres representantes dos movimentos negro, de bairros e de favelas. A perspectiva de ação do coletivo partia do entendimento de que todas as mulheres negras, independentemente a qual classe socioeconômica pertencessem, eram discriminadas pelo racismo e pelo sexismo. Entre as fundadoras e principais participantes do grupo estavam Lélia Gonzalez, Elizabeth Viana, Rosália Lemos, Jurema Batista e Geralda Alcântara (Gonzalez, 1985; Viana, 2010).

O nome do coletivo vincula-se à preocupação em resgatar um passado histórico, homenageando a rainha africana Nzinga (1583-1663) e sua luta para enfrentar o 
colonialismo português em Angola. Além disso, as referências simbólicas continuam nas cores da logomarca adotada pelo grupo e utilizadas posteriormente também no jornal, que fazem alusão à cosmologia religiosa afro-brasileira e aos movimentos feministas: o amarelo de Oxum e o roxo do movimento internacional de mulheres. O pássaro presente na logomarca significava a ancestralidade feminina, na tradição nagô (Gonzalez, 1985; Ratts; Rios, 2010). O nome foi uma sugestão de Lélia Gonzalez, a primeira coordenadora do coletivo, a partir de pesquisas que realizou sobre a história das mulheres africanas e o poder exercido por elas (Viana, 2006). Nzinga se transformou, ao longo dos séculos, em símbolo de luta, como guerreira e estrategista. Assim, a escolha da simbologia da organização refletia as relações que definiam o coletivo - o movimento negro e o feminista, embora com a predominância das mulheres negras, por meio da representação da rainha angolana (Barreto, 2005).

O grupo tinha como objetivo trabalhar com mulheres negras de baixa renda, a começar pelo local escolhido para sediar as atividades - a sede da Associação do Morro dos Cabritos, zona oeste do Rio de Janeiro -, uma demanda latente dos movimentos negro e feminista da época, articulando a discussão sobre gênero e raça. Ratts e Rios (2010) consideram a experiência do coletivo muito interessante por ter buscado desenvolver na prática as categorias de raça, classe e gênero, como é ressaltado no primeiro número do periódico:

Um COLETIVO DE MULHERES NEGRAS, porque aí se encontra a nossa especificidade, a nossa diferença. Por sermos MULHERES, pensamos, agimos, sentimos diferentes dos homens. Sendo NEGRAS, herdeiras em maior ou menor grau da cultura africana, temos um modo de sentir, agir, pensar diferentes das mulheres não negras. Além do sexismo, lutamos contra o racismo e a discriminação racial, que fazem de nós o setor mais explorado e mais oprimido da sociedade brasileira (Nzinga Informativo, 1985, p. 2).

Posteriormente, essa experiência seria ampliada com a publicação do Nzinga Informativo, a partir da aprovação do projeto História contemporânea das lutas das mulheres negras, que forneceu ao grupo um apoio financeiro da instituição estadunidense Global Ministries (agência especializada da United Methodist Church), de Nova York, que também financiou 
outras atividades do coletivo. Foram publicados cinco números do jornal: junho/1985, julho/1985, fevereiro-março/1986, julho-agosto/1988 e março/1989. As quatro primeiras edições circularam com seis a oito páginas, sem assinatura na maioria dos textos. Entretanto, a edição número 5 se difere das anteriores pelo tamanho - sendo publicado em 16 páginas -, além de trazer a cobertura do $1^{\circ}$ Encontro Nacional de Mulheres Negras (ocorrido em dezembro de 1988, em Valença, RJ), com textos-depoimento assinados por representantes de diversos coletivos de mulheres negras de vários estados brasileiros, o que demonstra a ramificação atingida pelo informativo e o diálogo existente entre os grupos em atuação naquele momento.

O artigo Racismo e machismo, escrito por Pedrina de Deus, à época membro do Conselho Estadual dos Direitos da Mulher do Rio de Janeiro, publicado no número 4, de julho/agosto de 1988, é um exemplo interessante quanto ao destaque que a subjugação conjugada de gênero, raça e classe tinha na agenda do grupo e, consequentemente, do jornal. Os "aparelhos ideológicos do Estado" (escola, religião, família, meio de comunicação, entre outros) foram apontados como responsáveis por difundir a ideia de que a população negra seria explorada por ser incapaz de agir por seus próprios méritos, em razão de ser inferior aos brancos. O mito da democracia racial seria outra vertente da aculturação dessa parcela da população, em favor do padrão hegemônico. Às mulheres negras caberia o peso maior, já que a colonização racista as reduziu a "promotoras de prazer sexual e gastronômico do homem".

\footnotetext{
Porque nasceu mulher, a mulher negra já cresce numa situação de desvantagem em relação a qualquer outro membro da sociedade. Ela vai recebendo desde pequena a informação de que a servidão está na sua natureza de mulher e de negra. E, à medida que ela vai se convencendo de que sua posição é de dependência em relação ao homem e em relação aos brancos, ela se torna um ser passivo diante da sociedade. (Deus, 1988, p. 4-5).
}

Essa reflexão de Pedrina de Deus vincula-se também aos sérios embates que as mulheres negras sofreram (e sofrem) dentro do próprio movimento negro, no sentido de muitos ativistas entenderem que a força em favor da luta contra o racismo não poderia ser dividida com reivindicações específicas, como era o caso da agenda das mulheres negras. "Fora de 
nossas casas os homens negros pensam que a luta contra o racismo está avançando. Mas nenhuma luta avança quando uma parcela desse grupo estiver oprimida e explorada" (Deus, 1988, p. 5).

Davis (2016, p. 232-233) ressalta que as mulheres negras nunca tiveram "como foco central de sua vida as tarefas domésticas", escapando, assim, "ao dano psicológico que o capitalismo industrial impôs às donas de casa brancas de classe média, cujas supostas virtudes eram a fraqueza feminina e a submissão de esposa”. Em contrapartida, as mulheres negras tiveram que ser fortes para lutar pela sobrevivência de sua família e de sua comunidade. As mulheres negras, continua a autora, pagaram um preço alto por sua força e relativa independência: embora raramente tenham sido "apenas dona de casa", sempre realizaram as tarefas domésticas, carregando o fardo duplo do trabalho assalariado e dos afazeres domésticos. O termo "matriarcado da miséria", utilizado por Carneiro (2011, p. 130), complementa a reflexão de Davis ao sintetizar em si como a "experiência histórica [das mulheres negras brasileiras é] marcada pela exclusão, pela discriminação e pela rejeição social", além de "revelar, a despeito dessas condições, o seu papel de resistência e liderança em suas comunidades miseráveis em todo o país".

A valorização da população negra e, em especial, das mulheres negras, é o ponto central do Nzinga Informativo, por meio de temas ligados à comunidade negra, às organizações de mulheres e sua inserção na política institucional. No que se refere à comunidade negra, o jornal aborda assuntos como discriminação racial, movimentos negros, mulheres negras, cultura negra e escritoras/es negras/os, prezando pela divulgação e valorização de seus ritos e costumes. Um dos temas significativos do debate trazido pelo veículo é a discriminação racial em andamento na África do Sul, por meio do apartheid, na época de sua circulação. As críticas à política racial não eram apenas para chamar a atenção do que acontecia no país africano, mas também servia como alerta para a segregação interseccional - raça, classe e gênero - que ocorria (e ainda ocorre) no Brasil e que restringe o acesso à cidadania plena.

Todas as iniciativas promovidas pelo grupo tinham como tônica a importância do movimento de mulheres negras se organizar sob outras vertentes que não as do feminismo 
hegemônico, sendo recorrente nas cinco edições da publicação, visto que também era o direcionamento que conduzia o próprio coletivo.

Enquanto Grupo de Mulheres Negras, nós do NZINGA entendemos a necessidade da nossa articulação com o Movimento de Mulheres e com o Movimento Negro, na medida em que os debates, as reflexões e o embasamento que norteiam nossa atuação devem estar centrados em dois eixos: o primeiro $\mathrm{a}$ [s] questões do Gênero: SOMOS MULHERES - e como tal submetidas à discriminação sexual por que passam todas as mulheres, independente de raça etnia, classe social ou credo religioso. O segundo - a questão da Etnia: SOMOS NEGRAS - e o que nos diferencia das demais mulheres não é só a cor da pele, mas a IDENTIDADE CULTURAL. E é para resgatar esta identidade de MULHER NEGRA, que precisamos nos organizar à parte sim. Aprofundar as questões específicas, perceber onde, como e quando somos oprimidas e partindo deste específico participarmos mais fortalecidas da luta geral. (Nzinga Informativo, 1988, p. 2).

A defesa da identidade das mulheres negras e de sua luta específica como mulheres negras, pilar dos editorais da publicação, vincula-se à discussão feita por Gonzalez (1985), uma das fundadoras do grupo, como já mencionado. Para a ativista e intelectual, o movimento de mulheres negras tinha sua origem muito mais atrelada ao movimento negro do que ao movimento feminista, uma vez que é a partir da discriminação racial que as mulheres negras se percebem sofrendo a dupla opressão, tanto em relação a homens e mulheres brancas, quanto aos próprios companheiros do movimento - os homens negros. Essa ligação com o movimento negro concernia à identidade cultural de raiz africana, com valores e crenças distintos dos que vigoravam (ou vigoram) entre a população branca. Dessa forma, as mulheres negras buscavam uma dupla afirmação com sua agenda específica, ao mesmo tempo, no movimento negro e nos movimentos de mulheres e feminista.

Na mesma direção, a intelectual estadunidense bell hooks (2015), critica o entendimento generalizado de que "todas as mulheres são oprimidas":

O sexismo, como sistema de dominação, é institucionalizado, mas nunca determinou de forma absoluta o destino de todas as mulheres nesta sociedade. Ser oprimida significa ausência de opções. [...] Muitas mulheres nesta sociedade têm escolhas (por mais inadequadas que possam ser); portanto, exploração e 
discriminação são palavras que descrevem com mais precisão a sorte coletiva das mulheres nos Estados Unidos (hooks, 2015, p. 197, grifo da autora).

Em contrapartida, a autora ressalta que seu entendimento como feminista não ocorreu em razão dos debates capitaneados pelas mulheres brancas e de classe média, que, muitas vezes, acreditam estar libertando as mulheres não-brancas de um sofrimento que não sabiam existente. Mesmo que tenha sido criada em uma família negra do sul dos Estados Unidos, de classe trabalhadora e dominada pelo pai, ela tinha informações que lhe fizeram conhecer o cotidiano das mulheres brancas, tanto do sul quanto do norte do país. Entretanto, essa reciprocidade não ocorria, segundo ela, principalmente com as mulheres brancas do norte, que não percebiam seu lugar como privilegiado e que pouco incorporavam em sua agenda de luta feminista outras realidades que não a em que estivessem inseridas.

Resistimos à dominação hegemônica do pensamento feminista insistindo que ele é uma teoria em formação, em que devemos necessariamente criticar, questionar, reexaminar e explorar novas possibilidades. Minha crítica persistente foi construída por minha condição de membro de um grupo oprimido, por minha experiência com a exploração e a discriminação sexistas e pela sensação de que a análise feminista dominante não foi a força que moldou minha consciência feminista. [...] Minha consciência de luta feminista foi estimulada pela circunstância social. [...] o fato de as mulheres brancas de classe média e alta precisarem de uma teoria para "informá-las de que são oprimidas" era apenas mais uma indicação de suas condições de vida privilegiadas. (hooks, 2015, p. 202-203).

Essas reflexões de hooks (2015) dialogam com a perspectiva de Spelman (1988), que entende as críticas às teóricas feministas brancas e de classe média muito mais vinculadas a uma falta de espaço para que esses grupos excluídos se coloquem e se apresentem como sujeitos por si mesmos do que uma inclusão de características. A diferença, para Spelman (1988), tem o sentido de privilégio.

Fazendo eco às discussões anteriores, quase 30 anos depois do primeiro número do Nzinga Informativo ser distribuído, um grupo de mulheres formado, em sua maioria, por negras, moradoras de diferentes regiões periféricas da cidade de São Paulo e jornalistas, criou o coletivo Nós, Mulheres da Periferia, em 2012, dando origem também ao site e à página no Facebook. Na atualização das nomenclaturas da imprensa alternativa das décadas de 1970 
e 1980, apresentam-se como um "coletivo jornalístico independente, transparente e apartidário", cuja principal diretriz é difundir "conteúdos autorais produzidos por mulheres e a partir da perspectiva de mulheres, tendo como fio condutor editorial a intersecção de gênero, raça, classe e território". As integrantes do grupo são: Jéssica Moreira, Semayat Oliveira, Cíntia Gomes, Bianca Pedrina, Mayara Penina, Priscila Gomes, Regiany Silva, Lívia Lima e Aline Kátia Melo. O marco fundador foi um manifesto publicado no jornal Folha de S. Paulo, no qual retratavam suas experiências cotidianas e os enfrentamentos diários quanto às desvantagens de raça, classe e gênero:

\begin{abstract}
Somos maioria. Somos minoria. Pobres, pretas, brancas, periféricas. Migrante, nordestina, baianinha, quilombola, indígena. [...] Somos as mães que trabalham para as filhas estudarem. Somos as filhas que se formam na universidade para as mães voltarem para a escola. Somos operárias, empreendedoras, manicures, jornalistas, costureiras, motoristas, advogadas. Somos esposas, mães, irmãs, primas, tias, comadres, vizinhas. Somos a menina que não pode brincar de bolinha de gude, nem de carrinho de rolimã. Somos a irmã que cuida dos irmãos mais novos até a mãe voltar do serviço. E que lava a louça do almoço enquanto o irmão vai jogar bola. [...] Somos avós que criam os frutos da gravidez na adolescência. Somos aquelas que amam os filhos da patroa. Somos quem dá conta do recado quando nossos homens faltam. As que seguram as pontas quando são presos. Somos quem chora quando nossos filhos são mortos por serem suspeitos. Somos mães de maio, de junho, setembro... [...] Somos quem cria os abaixo-assinados para pedir creches. Somos quem trabalha em mutirão carregando bloco e fazendo marmita. Somos quem denuncia que a vizinha apanha do marido. [...] (Nós Mulheres da Periferia, 2012, s.p.) ${ }^{6}$.
\end{abstract}

A partir desse texto inaugural, o coletivo recebeu apoio e adesão de várias outras mulheres, que se sentiram contempladas naquelas palavras. Afinal, o manifesto era interseccional e, de fato, essas mulheres estavam representadas e retratadas ali. Ao falar sobre dupla jornada, divisão sexual do trabalho, dupla moral sexual, "matriarcado da miséria", desvalorização mercantil do trabalho de cuidado, o manifesto chama a atenção para diversos problemas que não surgiram inesperadamente, tampouco são de fácil resolução. Falava-se de questões que são colocadas em último plano nas discussões agendadas pela grande mídia, pelas políticas públicas, por pessoas - mulheres e homens - que não se sentem compelidos a

\footnotetext{
${ }^{6}$ Disponível em: <http://nosmulheresdaperiferia.com.br/manifesto/>. Acesso em: 9 nov. 2017.
} 
olhar além de seu convívio para perceber que há realidades bem diferentes daquela na qual se inserem.

Em ambas as plataformas - site e página no Facebook -, o coletivo se propõe a ser um meio para "reduzir o espaço vazio existente na imprensa e a falta de representatividade, buscando mais protagonismo e visibilidade", por meio da voz de cada uma das integrantes e de várias outras mulheres que são chamadas a contar suas histórias como protagonistas de suas vidas, não coadjuvantes de memórias esquecidas. A visibilidade trazida por esses canais é vista por elas como uma estratégia que vai além de informar e divulgar ações: ao se tornar um canal de diálogo sobre mulheres da periferia e colocar esse tema em discussão, a partir da produção de conhecimento e da reunião de histórias e experiências, esperam fomentar conteúdo em outros veículos e incidir politicamente (Marques; Freitas, 2017, p. 25).

Tal entendimento converge para a conceituação de Varikas $(2014$, p. 88), quanto à figura do pária, ao ser "reconhecido prioritariamente por 'sua' diferença, marcado/a como membro de uma categoria à parte, mesmo se desfruta formalmente de uma igualdade de direitos". A campanha “\#eumulherdaperiferia”, desenvolvida em 2014, para a qual diversas mulheres de diferentes idades e raças enviaram fotos segurando uma placa com a hashtag, é bastante significativa para pensar o debate sobre construção de si, reconhecimento e as duas consequências da construção da diferença, segundo Varikas (2014): dentro/fora e visibilidade/invisibilidade. Segundo a autora, para as pessoas consideradas "párias", o sentido de pertencimento é ambíguo, uma vez que se está inserido em determinada sociedade ou comunidade, ao mesmo tempo em que, não é reconhecido ou legitimado como sujeito de direitos perante as outras pessoas, justamente por ser "o/a diferente" em relação ao grupo dominante.

A aba "Nossas vozes", localizada na parte superior do site, traz textos escritos em primeira pessoa, no formato de depoimentos que englobam assuntos diversos como educação, saúde, infância e direitos. Deflagrados a partir de algum fato noticioso do momento, os textos da coluna, diferentemente da grande mídia, não apresentam aspas de especialistas renomados ou de estudiosos da área. Seu foco está no que as mulheres que são diretamente impactadas por aqueles problemas têm a dizer. Em outras palavras, é exercido o 
protagonismo delas, com respeito a seu lugar de fala, ou seja, há uma "tentativa de analisar discursos diversos a partir da localização de grupos distintos e mais, a partir das condições de construção do grupo no qual funciona" (Ribeiro, 2017, p. 58), o que permitiria a quebra de uma visão dominante.

No dia 17 de janeiro de 2018, a coluna esteve a cargo da mestra em Biologia pela Universidade Federal de São Paulo (Unifesp) Juliete Vitorino, a fim de repercutir os dados divulgados quanto à participação de estudantes na edição de 2017 do Exame Nacional do Ensino Médio (ENEM). A abertura do texto lembra das condições desiguais a que candidatos e candidatas - em especial, as mulheres da periferia - passam pelo processo de ingresso e permanência nas universidades:

\begin{abstract}
Nesta semana, uma pesquisa sobre o ENEM (Exame Nacional do Ensino Médio) de 2017 mostrou que $72 \%$ dos estudantes que tiraram as mil maiores notas do exame são meninos, mesmo as garotas sendo maioria no total das inscrições. Os números mostram não apenas uma disparidade de gênero, mas também racial. Dentre as notas mais altas, que são aquelas acima de 781,68 , só $6 \%$ são de jovens negras, enquanto os meninos brancos totalizaram quase $50 \%$ das melhores notas, no entanto, representam $15 \%$ dos inscritos. Esses números não são isolados, são recorrentes diante de nossa realidade enquanto mulheres periféricas.
\end{abstract}

Este não é um cenário isolado e se repete constantemente como fruto de uma sociedade que traz a desigualdade de classe e de raça fincada em suas raízes. A entrada, no entanto, é apenas um dos fatores, depois há o desafio da permanência, assim como de enfrentar o preconceito e discriminação dentro do espaço universitário. (Vitorino; Moreira, 2017, s.p) ${ }^{7}$.

Na sequência, a bióloga relata sua vivência durante o curso de graduação e mestrado, repleta de restrições por não se sentir integrada e pertencente àquele ambiente. Não por ser incapaz de desenvolver o que era de praxe para sua formação, mas por se deparar, a todo momento, com atitudes e comentários reprobatórios quanto a ser uma mulher negra e periférica, pleiteando um status que lhe fora negado por séculos.

\footnotetext{
${ }^{7}$ Disponível em: <http://nosmulheresdaperiferia.com.br/quem-somos/>. Acesso em: 9 nov. 2017.
} 
Ser uma pessoa negra dentro da universidade é fazer pelo menos duas vezes o que todo mundo faz uma vez dentro da sala de aula, para que percebam que você está ali e ainda fazer por fora, para garantir não só a sobrevivência de todos que estão ali, mas permitir que aqueles que vêm depois de nós tenham uma caminhada mais tranquila, e possam de fato estar ali só para estudarem.

Alguns professores duvidavam da minha capacidade e cheguei a receber nota inferior, mesmo tendo feito tudo o que todo mundo fez. (Vitorino; Moreira, 2017, s.p.) $)^{8}$.

O depoimento de Juliete Vitorino, que segue à apresentação, reforça o que Gonzalez (1985, p. 95) frisa sobre o racismo: "[...] enquanto articulação ideológica e conjunto de práticas, denota sua eficácia estrutural na medida em que remete a uma divisão racial do trabalho extremamente útil e compartilhada pelas formações socioeconômicas capitalistas e multirraciais contemporâneas". Ao se colocar como um espaço de difusão dessas vozes, por vezes silenciadas pela opressão interseccional, o Nós, Mulheres da Periferia, assim como o Nzinga Informativo, contribuem para a pluralidade de discursos e perspectivas, a fim de que desigualdades e assimetrias possam ser reduzidas nos mais diversos espaços de atuação política e comunicacional.

\section{Considerações finais}

O conceito de "contrapúblicos subalternos", que Fraser (1999) cunha ao criticar o modelo excludente da esfera pública habermasiana, pode ser perfeitamente associado à imprensa alternativa. Especificamente, a imprensa feminista - e sua discussão interseccional, de décadas anteriores e da atualidade -, que questiona e afronta esse ideal de esfera pública e a exclusão de vários grupos dela, pode ser percebida como um contrapúblico subalterno empoderado e empoderador.

\footnotetext{
${ }^{8}$ Disponível em: <http://nosmulheresdaperiferia.com.br/nossas-vozes/ser-negra-dentro-da-universidade-efazer-o-dobro-para-ser-reconhecida/>. Acesso em: 11 fev. 2018.

${ }^{9}$ Fraser (1999) entende que, ao se utilizar de uma separação para (de)limitar mecanismos de participação de outros estilos de comportamento político e normas alternativas de discurso político, o conceito de esfera pública de Habermas também deslegitima debates fundamentados em argumentos alheios ao perfil do indivíduo marcado pelo ideal liberal.
} 
Mesmo que ainda de forma imperfeita e com acesso um tanto restrito devido a razões socioeconômicas, as mídias digitais se apresentam como um espaço de empoderamento para novos entrantes, atrizes e atores em papéis de protagonistas do discurso, que questionam o modelo excludente da esfera pública habermasiana. Além disso, a organização de coletivos que se pautam a partir de outras perspectivas que não a do feminismo eurocêntrico, branco, de classe média e heteronormativo, seja nos idos da redemocratização, via jornais que chegavam pelos correios, seja na era da internet, com notícias frescas ao piscar de olhos, representa distintas maneiras de se construir os sujeitos políticos.

As mulheres negras, ao se mobilizarem em prol de uma agenda contra a hierarquização de raça, classe e gênero - inclusive entre as próprias mulheres -, têm nos veículos jornalísticos ferramentas estratégicas de efetivação do debate e da amplificação de suas vozes, há tanto deslegitimadas e silenciadas. Gomes (2017) compreende o corpo negro a partir de processos emancipatórios e libertadores, assim como reguladores e opressores. Ao tensionar os cânones da ciência moderna, os discursos hegemônicos e a agenda da grande mídia, os movimentos de mulheres negras respondem à política do corpo regulado - aquele estereotipado por um conjunto de representações que o objetificam e lhe retiram a existência - com a luta pela emancipação social do negro (em especial, das mulheres negras) como sujeito.

Esse corpo político produz saberes que questionam a hierarquização social, que transpassa o período escravocrata e chega aos nossos dias com nova roupagem: "de incapacidade moral à incapacidade física e intelectual; de sexualidade exacerbada ao mito da 'mulata' sensual" (Gomes, 2006, p. 155). Nzinga Informativo e Nós, Mulheres da Periferia, cada um em seu contexto, de suas ações como coletivo e das plataformas disponíveis, buscam romper a coisificação das mulheres negras - advinda do entrelaçamento entre raça, classe e gênero - com a expressão cotidiana de cidadania, na expressão de distintas vozes que ecoam em prol de sua integração da sociedade brasileira. 


\section{Notas}

1. Este artigo foi produzido durante residência pós-doutoral da autora, em andamento no Programa de Pós-graduação em Ciência Política, da Universidade Federal de Minas Gerais (PPGCP/UFMG). Ele foi realizado com apoio do Conselho Nacional de Desenvolvimento Científico e Tecnológico ( $\mathrm{CNPq}$ - Brasil). A residência pós-doutoral vincula-se à pesquisa "Protestos e engajamento político: discurso e identidade em manifestações contemporâneas", aprovada no Edital de Chamada Universal n. 14/2014, do MCTI/CNPq, e no Edital Universal 01/2015, da Fundação de Amparo à Pesquisa de Minas Gerais (FAPEMIG). Também se relaciona com o projeto interinstitucional "Transformações do ativismo no Brasil: junho de 2013 em perspectiva comparada", aprovado no edital sobre Memórias Brasileiras - Conflitos Sociais n. 12/2015, da Coordenação de Aperfeiçoamento de Pessoal de Nível Superior (CAPES), que envolve colaboração de pesquisadores de seis universidades nacionais (UERJ, UFG, UFES, UFMG, UFRGS e UFPel).

2. Versões iniciais deste artigo foram apresentadas no I Encontro Nacional da Nova Rede de Pesquisas em Feminismos e Política, em Brasília (fevereiro/2018) e no XXVII Encontro Anual da Compós, em Belo Horizonte (junho/2018). Registro aqui meus agradecimentos aos comentários recebidos, que muito contribuíram para sua revisão. Em especial, meu muito obrigada a Fernanda Mota e Flavia Rios.

\section{Referências}

BARRETO, R. A. Enegrecendo o feminismo ou feminizando a raça: narrativas de libertação em Angela Davis e Lélia Gonzalez. 2005. Dissertação (Mestrado) - Pontifícia Universidade Católica do Rio de Janeiro, Departamento de História, Rio de Janeiro.

BIROLI, F.; MIGUEL, L. F. Gênero, raça, classe: opressões cruzadas e convergências na reprodução das desigualdades. Mediações, Londrina, v.20, n.2, p.27-55, jul./dez. 2015.

BORGES, A. Mulherio, um jornal feminista. Comunicação e Sociedade, São Paulo, n.8, p.125133, nov./1982.

BUITONI, D. S. Mulher de papel: a representação da mulher pela imprensa feminina brasileira. São Paulo: Summus, 2009.

CARDOSO, E. Imprensa feminista brasileira pós-1974. Revista Estudos Feministas, Florianópolis, v.12, número especial, p.37-55, set./dez. 2004.

CARNEIRO, S.. Mulheres em movimento. Estudos Avançados, São Paulo, v.17, n.49, p.117-132, 2003.

O matriarcado da miséria. In: CARNEIRO, S. Racismo, sexismo e desigualdade no Brasil. São Paulo: Selo Negro, 2011. p.127-130.

COLLINS, P. H. Aprendendo com a outsider within: a significação sociológica do pensamento feminista negro. Revista Sociedade e Estado, Brasília, v.31, n.1, p.99-127, jan./abr. 2016.

COSTA, J. B. Controle de vida, interseccionalidade e política de empoderamento: as organizações políticas das trabalhadoras domésticas no Brasil. Estudos Históricos, Rio de Janeiro, v.26, n.52, p.471-489, jul./dez. 2013. 
CRENSHAW, K. A interseccionalidade na discriminação de raça e gênero. s.d. Disponível em: <http://www.acaoeducativa.org.br/fdh/wp-content/uploads/2012/09/Kimberle-Crenshaw.pdf>. Acesso em: 16 dez. 2015.

Documento para o Encontro de especialistas em aspectos da discriminação racial relativos ao gênero. Revista Estudos Feministas, Florianópolis, v.10, n.1, p.171-187, 2002.

DAVIS, A. Mulheres, raça e classe. Trad. Heci Regina Candiani. São Paulo: Boitempo, 2016.

DEUS, P. de. Racismo e machismo. Nzinga Informativo, Rio de Janeiro, n.4, p.4-5, jul./ago. 1988.

FRASER, N. Repensando la esfera pública: una contribución a la crítica de la democracia actualmente existente. Revista Ecuador Debate, Quito-Ecuador, n.46, p.139-173, abr. 1999.

FREITAS, V. De qual feminismo estamos falando? Desconstruções e reconstruções das mulheres, via imprensa feminista brasileira, nas décadas de 1970 a 2010. 2017. Tese (Doutorado) - Universidade de Brasília, Instituto de Ciência Política, Brasília.

GODARD, B. Feminist periodicals and the production of cultural value: the Canadian context. Women's Studies International Forum, Oxford; New York, v.25, n.2, p.209-223, 2002.

GOMES, N. L. O processo de rejeição/aceitação/ressignificação do corpo e do cabelo. In: GOMES, N. L. Sem perder a raiz: corpo e cabelo como símbolos da identidade negra. Belo Horizonte: Autêntica, 2006. p.133-188.

Corporeidade negra e tensão regulação-emancipação social: corpo negro regulado e corpo negro emancipado. In: GOMES, N. L. O movimento negro educador: saberes construídos nas lutas por emancipação. Petrópolis: Vozes, 2017. p.93-100.

GONZALEZ, L. Mulher negra. Afrodiáspora, Brasília, v.6 e 7, n.19, p.94-106, 1985.

O movimento negro na última década. In: GONZALEZ, L.; HASENBALG, C. Lugar de negro. Rio de Janeiro: Marco Zero, 1982. p.9-66.

Racismo e sexismo na cultura brasileira. Revista Ciências Sociais Hoje, São Paulo, p.223-244, 1984.

HOOKS, b. Intelectuais negras. Revista Estudos Feministas, Florianópolis, p.464-478, 2.sem. 1995.

Mulheres negras: moldando a teoria feminista. Revista Brasileira de Ciência Política, Brasília, n.16, p.193-210, jan./abr. 2015.

INSTITUTO DE PESQUISA ECONÔMICA E APLICADA (IPEA) et al. (Brasil). Retratos da desigualdade de gênero e raça. 5.ed. Brasília: IPEA, 2017. Disponível em: <http://www.ipea.gov.br/retrato/indicadores.html>. Acesso em: 19 jul. 2017.

INSTITUTO DE PESQUISA ECONÔMICA E APLICADA (IPEA) (Brasil).; FÓRUM BRASILEIRO DE SEGURANÇA PÚBLICA (FBSP) (Brasil). Atlas da Violência 2018. Rio de Janeiro: IPEA, 2018. Disponível em: 
$<$ http://www.ipea.gov.br/portal/imagens/stories/PDFs/relatorio_institucional/180604_atlas_da_viol encia_2018.pdf>. Acesso em: 29 jun. 2018.

KUCINSKI, B. Jornalistas e revolucionários: nos tempos da imprensa alternativa. São Paulo: Página Aberta, 1991.

MARQUES, A. C. S.; FREITAS, V. G. Gênero, autonomia e subjetivação política de mulheres negras no Brasil. Líbero, São Paulo, n.40, p.16-28, ago./dez. 2017.

NÓS MULHERES DA PERIFERIA (São Paulo). Quem somos. Disponível em: <http://nosmulheresdaperiferia.com.br/quem-somos/>. Acesso em: 9 nov. 2017.

NZINGA INFORMATIVO. Editorial. Nzinga Informativo. Rio de Janeiro, p. 2-2. jul/ago 1988.

NZINGA INFORMATIVO. O QUE é o Nzinga?: Um coletivo de mulheres negras. Nzinga Informativo. Rio de Janeiro, p. 2-2. jun. 1985.

PINTO, C. R. J. Uma história do feminismo no Brasil. São Paulo: Editora Fundação Perseu Abramo, 2007.

RATTS, A.; RIOS, F. Lélia Gonzalez. São Paulo: Selo Negro, 2010.

RIBEIRO, D. O que é lugar de fala? Belo Horizonte: Letramento: Justificando, 2017.

RIOS, F. A cidadania imaginada pelas mulheres afro-brasileiras: da ditadura militar à democracia. In: BLAY, E. A.; AVELAR, L. (Org.). 50 anos de feminismo: Argentina, Brasil e Chile, a construção das mulheres como atores políticos e democráticos. São Paulo: Editora da Universidade de São Paulo, FAPESP, 2017, p.227-253.

RIOS, F.; FREITAS, V. G. Nzinga Informativo: redes comunicativas e organizacionais na formação do feminismo negro brasileiro. Cadernos Adenauer, São Paulo, n.1, p.25-45, 2018.

RIOS, F.; RATTS, A. A perspectiva de Lélia Gonzalez. In: PINTO, A. F. M.; CHALHOUB, S. (Org.). Pensadores negros - pensadoras negras: Brasil, séculos XIX e XX. Cruz das Almas: EDUFRB; Belo Horizonte: Fino Traço, 2016, p.387-403.

RODRIGUES, C. S.; PRADO, M. A. M. Movimento de mulheres negras: trajetória política, práticas mobilizatórias e articulações com o estado brasileiro. Psicologia \& Sociedade, Belo Horizonte, v.22, n.3, p.445-456, 2010.

SPELMAN, E. Inessential woman: problems of exclusion in feminist thought. Boston: Beacon Press, 1988.

VARIKAS, E. O que é um pária? In: VARIKAS, E. A escória do mundo: figuras do pária. São Paulo: Editora Unesp, 2014. p.69-94.

VIANA, E. E. S. Lélia Gonzalez e outras mulheres: pensamento feminista negro, antirracismo e antissexismo. Revista da ABPN, Rio de Janeiro, v.1, n.1, p.52-63, mar./jun. 2010.

Relações raciais, gênero e movimentos sociais: o pensamento de Lélia Gonzalez (1970-1990). 2006. Dissertação (Mestrado) - Universidade Federal do Rio de Janeiro, Departamento de História, Instituto de Filosofia e Ciências Sociais, Rio de Janeiro. 
VITORINO, J; MOREIRA, J. Ser negra dentro da universidade é fazer o dobro para ser reconhecida. 2018. Disponível em: <http://nosmulheresdaperiferia.com.br/nossas-vozes/sernegra-dentro-da-universidade-e-fazer-o-dobro-para-ser-reconhecida/>. Acesso em: 11 fev. 2018.

WERNECK, J. Nossos passos vêm de longe! Movimentos de mulheres negras e estratégias políticas contra o sexismo e o racismo. Revista da ABPN, Rio de Janeiro v.1, p.8-17, mar./jun. 2010.

\section{A autora}

Viviane Gonçalves Freitas é pós-doutoranda no Departamento de Ciência Política, da Universidade Federal de Minas Gerais (DCP/UFMG). Bolsista PDJ/CNPq (Processo 168943/2017-4). Doutora em Ciência Política (UnB). Integrante do Margem - Grupo de Pesquisa em Democracia e Justiça (DCP/UFMG), do Grupo de Pesquisa sobre Democracia e Desigualdades (Demodê/IPOL/UnB) e da Rede de Pesquisas em Feminismos e Política. vivianegoncalvesfreitas@gmail.com 